\title{
Risk factors for extubation failure in mechanically ventilated children in pediatric intensive care unit
}

\author{
Supreet Khurana ${ }^{1}$, Siddharth Bhargava ${ }^{2}$, Puneet A Pooni ${ }^{3}$, Deepak Bhat ${ }^{3}$, Gurdeep Dhooria ${ }^{2}$, \\ Jatinder Goraya ${ }^{2}$, Kamaldeep Arora ${ }^{2}$, Shruti Kakkar ${ }^{4}$ \\ From ${ }^{1}$ Assistant Professor, Department of Neonatology, Government Medical College and Hospital, Chandigarh, ${ }^{2}$ Associate Professor, ${ }^{3}$ Professor, \\ ${ }^{4}$ Assistant Professor, Department of Pediatrics, Dayanand Medical College and Hospital, Ludhiana, Punjab, India
}

Correspondence to: Siddharth Bhargava, Department of Pediatrics, Dayanand Medical College and Hospital, Tagore Nagar, Ludhiana, Punjab, India (141001). E-mail: siddharthb27@gmail.com

Received - 30 May 2019

Initial Review - 17 June 2019

Accepted - 20 July 2019

\begin{abstract}
Background: Mechanical ventilation is lifesaving in children with respiratory failure. However, its unnecessary prolongation once a child is capable of sustaining spontaneous effective ventilation is associated with significant complications. Objective: To identify the factors that lead to higher chance of extubation failure in mechanically ventilated children. Materials and Methods: A prospective, observational study was conducted over a period of 1 year. Children admitted to pediatric intensive care unit of a tertiary care hospital of Northern India aged 1 month-17 years, needing mechanical ventilation were included in the study. Predefined criteria were used to decide the timing of extubation. Relevant details were recorded to study various patient-related parameters and their association with extubation outcome. Results: Mean age of the study group was 50 months with a male:female ratio of 3:1. Extubation failure rate was $14.5 \%$. Extubation failure was significantly higher in patients ventilated for $>7$ days $(p=0.01)$, those with the pediatric risk of mortality score $>10$ at admission ( $\mathrm{p}=0.009)$, in addition to peak inspiratory pressure $>16 \mathrm{~cm} \mathrm{H}_{2} \mathrm{O}(\mathrm{p}=0.009)$ and $\mathrm{FiO}_{2} \geq 0.35$ $(\mathrm{p}=0.01)$ before extubation. Accidental extubation was also associated with higher extubation failure $(\mathrm{p}<0.001)$. Conclusion: Our study demonstrates that even though sicker patients requiring ventilation for longer duration are more prone to failed extubations, protocol based, and planned extubations lead to better extubation success.
\end{abstract}

Key words: Accidental extubation, Duration of ventilation, Fraction of inspired oxygen, Peak inspiratory pressure, Pediatric risk of mortality score

$\mathrm{E}$ ndotracheal intubation and positive pressure ventilation are often required in critically ill infants and children with respiratory failure. While invasive mechanical ventilation is lifesaving, it can be associated with complications. Therefore, it is important that mechanical ventilation be discontinued as soon as the patient is capable of sustaining spontaneous effective breathing. Both premature extubation and unnecessary ventilation are hazardous [1]. Discontinuation of mechanical ventilation as soon as it is no longer needed is important to avoid respiratory complications and physiological dependence on sedatives and analgesics. The purpose of extubation is to achieve the transition from ventilator dependent to independent breathing in a smooth manner and avoiding stress to cardiorespiratory system [2].

Pre-extubation parameters are utilized to provide insight into reasons for patient's ventilator dependence and provide focus as to which therapeutic intervention needs to be implemented to prepare a patient for extubation. They also assist in the formulation of extubation plan targeted toward patient's specific needs. Extubation failure is defined as the need for reinstitution of ventilatory support within 24-72 h of planned extubation [3], which can be variable between 2 and $47 \%$ of extubated patients and is highest in preterm neonates (22-28\%) [4]. Pathophysiology of extubation failure can be distinct from that of weaning failure [5].

Paucity of literature on factors predicting extubation outcome in children, poor predictive value of weaning guidelines proposed for adults [6], and lack of sensitivity of indices developed for the prediction of extubation success [7] urged us to gain insight into this rather important aspect of mechanical ventilation. Hence, our study was done to evaluate the factors associated with extubation failure in children.

\section{MATERIALS AND METHODS}

This prospective, observational study was conducted over a period of 1 year on patients admitted to pediatric intensive care unit (PICU). All children between the age group of 1 month and 17 years requiring mechanical ventilation were included in the study. The children who refused to give consent for participation in the study or did not complete treatment in our hospital before extubation were excluded from the study.

The study was approved by the institutional ethics committee. The aim of the study was to determine the factors associated with 
extubation failure. After obtaining informed parental consent, detailed history, physical examination, relevant investigations, the course of the illness during hospital stay, management, final diagnosis, and the outcome of patients were documented.

\section{Extubation Protocol}

After weaning to the lowest possible ventilatory settings, patients were given spontaneous breathing trials (T-piece or pressure support $\leq 10 \mathrm{~cm}$ of $\mathrm{H}_{2} \mathrm{O}$ ). Those who passed the trial were planned for extubation. Sedation, analgesia, and feeds were stopped at least $4 \mathrm{~h}$ before planned extubation. Prophylactic steroid (one dose of IV dexamethasone $0.2 \mathrm{mg} / \mathrm{kg}$ ) was administered if the duration of intubation was $\geq 5$ days and repeated if deemed necessary after extubation [8]. Most of the patients were extubated to face mask oxygen and some to nasal prong/face mask CPAP/BiPAP, depending on the age of the child and availability of appropriate size of oxygen delivery device. Patient's cardiorespiratory status was monitored. Post-extubation stridor was treated with a single inhalation of nebulized adrenaline $(0.5 \mathrm{ml} / \mathrm{kg}$, $\max 4 \mathrm{ml}$ of $1: 1000$ dilution), repeated if necessary [9]. Severe stridor requiring reintubation was treated with IV dexamethasone $0.2 \mathrm{mg} / \mathrm{kg} / \mathrm{dose}$ $6 \mathrm{~h}$ for 2 days before the next extubation attempt.

The decision to wean and extubate was based on patient's clinical status, blood gas determination, and extent of ventilator support. The criteria followed for extubation are mentioned in Table 1.

The weaning and extubation protocol was followed in most patients, but some patients were extubated from higher levels of ventilator support due to unplanned/accidental extubation. Nonetheless, all the patients were included in data analysis. Extubation failure was defined as the need for reinstitution of ventilatory support within 24-72 h of planned endotracheal tube removal.

\section{Outcome Assessment}

Various factors were assessed with regard to their association with extubation outcome.

\section{Statistical Analysis}

Mean and standard deviations were computed. Chi-square or Fisher's exact test whichever was applicable was applied for comparing groups. Statistical analysis was done using the SPSS Version 20.

\section{RESULTS}

Four hundred and fifty children were admitted to the PICU during the study period of 1 year. Out of these, 85 children needed mechanical ventilation. Fifty-three patients met the inclusion criteria and were finally enrolled. The mean age of the study group was $50 \pm 49.9$ months with a male:female ratio of $3: 1$. Out of them, $28 \%$ of patients were brought in respiratory arrest. Majority of the patients $(87 \%)$ were ventilated for more than $72 \mathrm{~h}$ with an average duration of ventilation (DOV) of $6.9 \pm 4.4$ days. The most common indication for mechanical ventilation was respiratory disorder $(55 \%)$. Extubation success was significantly higher in this group $(p=0.004)$. Extubation failure rate was lowest in the patients with pneumonia (13\%). Other groups of conditions requiring mechanical ventilation were central nervous system disorders $(25 \%)$, neuromuscular diseases (11\%), and trauma (9\%).

A total of 53 patients underwent 62 extubation trials. Extubation failure rate was $14.5 \%$ (9 failures of 62 extubation attempts). Two patients had a single extubation failure (3.2\%). Two patients had two extubation failures each (6.5\%), of which one patient died and one was extubated successfully. One patient had three extubation failures $(4.8 \%)$ and had to be tracheostomized. Extubation failure was significantly higher in patients ventilated for $>7$ days $(27 \%)$ compared to those ventilated for $<7$ days $(6 \%),(p=0.01)$. Pediatric risk of mortality (PRISM) score $>10$ at admission also showed a strong association with extubation failure $(\mathrm{p}=0.009)$.

Extubation failure rate was maximum in infants (19\%) but was not statistically significant $(\mathrm{p}=0.25)$. With regard to the effect of nutritional status, patients with weight for age $>3^{\text {rd }}$ percentile had lesser failure rate $(10 \%)$ than those $<3^{\text {rd }}$ percentile $(24 \%)$, but the impact did not attain statistical significance $(p=0.08)$. Similarly, level of consciousness at admission as assessed by Glasgow coma scale did not show a strong association with extubation outcome. Out of the 62 extubations that took place during the study period, 49 were planned and 13 were unplanned (accidental) extubations. Reintubation was required in 6 of 13 patients ( $46 \%$ failure rate) in the accidental extubation group compared to 3 of 49 ( $6 \%$ failure rate) in the planned extubation group. Accidental extubation was

Table 1: Criteria followed for extubation in mechanically ventilated children in pediatric intensive care unit

\begin{tabular}{|c|c|c|}
\hline Clinical criteria & Ventilator-related criteria & $\begin{array}{l}\text { Laboratory-related } \\
\text { criteria }\end{array}$ \\
\hline Respiratory rate - (Breaths/min) & Expiratory tidal volume $\geq 5 \mathrm{ml} / \mathrm{kg}$ on a pressure & $\mathrm{ABG}$ \\
\hline$<1$ year $=30-60 / \mathrm{min}$ & support $\leq 10 \mathrm{~cm}$ of $\mathrm{H}_{2} \mathrm{O}$ & $\mathrm{pH}=7.35-7.45$ \\
\hline $1-3$ years $=25-40 / \mathrm{min}$ & $\mathrm{FiO}_{2} \leq 0.4$ & $\mathrm{pCO}_{2}=35-50 \mathrm{~mm}$ of $\mathrm{Hg}$ \\
\hline $4-5$ years $=20-35 / \mathrm{min}$ & $\mathrm{PEEP} \leq 5 \mathrm{~cm}$ of $\mathrm{H}_{2} \mathrm{O}$ & $\mathrm{PO}_{2}=\geq 80 \mathrm{mmHg}$ \\
\hline $6-12$ years $=18-30 / \mathrm{min}$ & $\mathrm{SpO}_{2} \geq 94 \%$ & $\mathrm{PCV}(\mathrm{Hct}) \geq 30$ \\
\hline $13-18$ years $=12-20 / \mathrm{min}$ & $\mathrm{PaO}_{2} / \mathrm{FiO}_{2}>200$ & \\
\hline Absence of significant retractions and paradoxical breathing & & S. electrolytes \\
\hline Minimal or no inotrope requirement & & $\mathrm{S} . \mathrm{Na}=135-145 \mathrm{mEq} / \mathrm{L}$ \\
\hline Glasgow coma scale $>10$ and good cough reflex & & $\mathrm{S} . \mathrm{K}=3.5-5 \mathrm{mEq} / \mathrm{L}$ \\
\hline
\end{tabular}


associated with significantly higher extubation failure compared to planned extubation $(\mathrm{p}<0.001)$.

The duration of mechanical ventilation was significantly increased in patients with accidental extubation. In this subgroup of patients with accidental extubations, the following ventilatory parameters showed significant association with extubation failure: Peak inspiratory pressure $(\mathrm{PIP}=\Delta \mathrm{PIP}$ (Peak inspiratory pressure above PEEP)+PEEP (Peak end-expiratory pressure) $>16 \mathrm{~cm} \mathrm{H}_{2} \mathrm{O}$ $(p=0.009)$ and fraction of inspired oxygen $\left(\mathrm{FiO}_{2}\right) \geq 0.35(\mathrm{p}=0.01)$ before extubation. The parameters affecting extubation are mentioned in Table 2.

Laboratory parameters (pre-extubation $\mathrm{ABG}$, hematocrit, and serum $\mathrm{K}+$ ) were not found to significantly affect extubation outcome. The most common complication seen in patients receiving mechanical ventilation was ventilator-associated pneumonia which was reported in $37 \%$ of cases followed by

Table 2: Factors affecting extubation in mechanically ventilated children

\begin{tabular}{|c|c|c|c|}
\hline Parameter & $\begin{array}{c}\text { Extubation } \\
\text { failure, n }(\%)\end{array}$ & $\begin{array}{c}\text { Extubation } \\
\text { success, n }(\%)\end{array}$ & p-value \\
\hline \multicolumn{4}{|l|}{ Age } \\
\hline$<1$ month & $04(19)$ & $17(81)$ & 0.25 \\
\hline$>1$ month & $05(12.2)$ & $36(87.8)$ & \\
\hline \multicolumn{4}{|l|}{ Gender } \\
\hline Male & $05(11)$ & $40(89)$ & 0.13 \\
\hline Female & $04(23.5)$ & $13(76.5)$ & \\
\hline \multicolumn{4}{|c|}{ Nutritional status (weight for age) } \\
\hline$\leq 3^{\text {rd }}$ centile & $05(23.8)$ & $16(76.2)$ & 0.08 \\
\hline$>3^{\text {rd }}$ centile & $04(9.8)$ & $37(90.2)$ & \\
\hline \multicolumn{4}{|c|}{ Glasgow coma scale at admission } \\
\hline$\leq 8$ & $05(17.2)$ & $24(82.8)$ & 0.29 \\
\hline$>8$ & $04(12.1)$ & $29(87.9)$ & \\
\hline \multicolumn{4}{|c|}{ Pediatric risk of mortality score at admission } \\
\hline$\leq 10$ & $02(5.3)$ & $36(94.7)$ & 0.009 \\
\hline$>10$ & $07(29.2)$ & $17(70.8)$ & \\
\hline \multicolumn{4}{|l|}{ Etiology for ventilation } \\
\hline Pneumonia & $02(13.3)$ & $13(86.7)$ & 0.92 \\
\hline Others & $07(14.9)$ & $40(85.1)$ & \\
\hline \multicolumn{4}{|l|}{ Duration of ventilation } \\
\hline$\leq 7$ days & $02(5.6)$ & $39(94.4)$ & 0.01 \\
\hline$>7$ days & $07(14.9)$ & $19(73)$ & \\
\hline \multicolumn{4}{|l|}{ Peak inspiratory pressure* } \\
\hline$\leq 16$ & $01(3.1)$ & $31(96.9)$ & 0.009 \\
\hline$>16$ & $08(26.7)$ & $22(73.3)$ & \\
\hline \multicolumn{4}{|l|}{$\mathrm{FiO}_{2}$} \\
\hline$\leq 0.35$ & $04(8.7)$ & $42(91.3)$ & 0.01 \\
\hline$>0.35$ & $06(35.3)$ & $11(64.7)$ & \\
\hline \multicolumn{4}{|c|}{ Ventilation-related complications } \\
\hline Stridor & $03(60)$ & $02(40)$ & 0.01 \\
\hline Accidental extubation & $06(46)$ & $07(54)$ & 0.0008 \\
\hline $\begin{array}{l}\text { Ventilator-associated } \\
\text { pneumonia }\end{array}$ & $06(26)$ & $17(24)$ & 0.032 \\
\hline
\end{tabular}

accidental extubation (21\%) and stridor (8\%). These complications were considerably higher in patients with failed extubation.

\section{DISCUSSION}

This was a prospective, observational study carried out with the aim to determine the factors associated with extubation failure. Mean age of the study population was 50 months in our study which was comparable to the study population assessed by Thiagarajan et al. and Hubble et al. [10,11]. Male preponderance of 3:1 was seen in our patients which was lower in Western population as gender bias is prevalent in our region $[12,13]$.

A longer DOV ( $>7$ days) and greater severity of the illness at admission, as assessed by the PRISM III score, were found to be important predictors of extubation failure. Accidental (unplanned) extubations were associated with significantly higher rates of extubation failure. Certain ventilatory parameters, namely, higher PIP and fraction of inspired oxygen $\left(\mathrm{FiO}_{2}\right)$ before extubation also correlated well with increased risk of extubation failure.

The most common group of conditions requiring mechanical ventilation in our study were pulmonary illnesses namely, pneumonia and ARDS. Other studies done by Mokhlesi et al., Oliveira and Filho, and Edmunds et al. also found similar observations $[5,14,15]$. Some Western studies quoted pneumonia while others found bronchiolitis to be the most common indication for mechanical ventilation. The extubation failure rate of $14.5 \%$ in our study is comparable to that seen by other authors. Thiagarajan et al. [10], Mokhlesi et al. [5], and Manczur et al. [16] found extubation failure rates of $11 \%$ and $13 \%$ each, respectively.

DOV $>7$ days had a significant association with extubation failure. Other studies are in agreement with regard to this finding, although the threshold DOV associated with extubation failure varied from 4 to 15 days [17-19]. In the study done by Manczur et al., the receiver operating characteristic curve identified the threshold value of DOV of $97 \mathrm{~h}$ (4 days) as a discriminator between successful and failed extubation with $78 \%$ sensitivity and $67 \%$ specificity [16]. We also found that patients who were sicker at admission (PRISM score $>10$ ) had higher extubation failure rates. These results were contradictory to the results obtained from other centers [17-19].

Even though our study showed a trend toward more extubation failures in malnourished children, the effect was not statistically significant. De Souza et al., 2012, reported higher duration of mechanical ventilation in malnourished children [20] which was in contrast to the results obtained by Fontela et al., 2005 [18]. A relatively small sample size in our study might be the reason for results not achieving statistical significance and a different conclusion compared to other studies with regard to the effect of nutritional status on extubation outcome.

Unplanned (accidental) extubation was found to be another significant risk factor for extubation failure, with $46 \%$ failure rate in our study. Unplanned extubation was also associated with a longer duration of mechanical ventilation. In a case-control study in an adult intensive care unit, an extubation failure rate of $47 \%$ 
was reported in patients with unplanned extubation [21], which is in concordance with our study.

In the subgroup of patients with unplanned extubation, ventilator-related parameters, namely, PIP $>16 \mathrm{~cm} \mathrm{H}_{2} \mathrm{O}$ before extubation and $\mathrm{FiO}_{2}>0.35$ were associated with greater extubation failure. Thiagarajan et al. found a statistically significant correlation between higher PIP and adverse extubation outcome $(\mathrm{p}=0.002)$ [10]. Similar results were reported by Farias et al. and Vallverdú et al. [22]. In the study by Engoren et al., $\mathrm{FiO}_{2}<0.53 \pm 0.08$ was a significant predictor of extubation success $(p=0.02)[23]$. The level of consciousness at admission and preextubation laboratory parameters (ABG, hematocrit, and serum $\mathrm{K}+$ ) did not impact extubation outcome.

The limitations of this study were the small sample size and short duration of the study. Another limitation was that all patients could not be extubated as per the planned protocol; but at the same time, this factor allowed us to analyze and compare the impact of protocol-based extubation with random extubation on the rate of extubation failure.

\section{CONCLUSION}

The findings of this study illustrate that even though sicker patients requiring ventilation for longer duration are more vulnerable to failed extubations, protocol based, and planned extubations contribute to better extubation success. Further future studies and more reliable methods are required to predict a child's readiness for extubation in a timely manner, thus avoiding undue prolongation of ventilator support. This study also emphasizes the need to take active measures to prevent untimely accidental extubations in PICU.

\section{REFERENCES}

1. Boles JM, Bion J, Connors A, Herridge M, Marsh B, Melot C, et al. Weaning from mechanical ventilation. Eur Respir J 2007;29:1033-56.

2. Epstein SK, Nevins ML, Chung J. Effect of unplanned extubation on outcome of mechanical ventilation. Am J Respir Crit Care Med 2000;161:1912-6.

3. Rothaar RC, Epstein SK. Extubation failure: Magnitude of the problem, impact on outcomes, and prevention. Curr Opin Crit Care 2003;9:59-66.

4. Saikia B, Kumar N, Sreenivas V. Prediction of extubation failure in newborns, infants and children: Brief report of a prospective (blinded) cohort study at a tertiary care paediatric centre in India. Springerplus 2015;4:827.

5. Mokhlesi B, TulaimatA, Gluckman TJ, Wang Y, Evans AT, Corbridge TC, et al. Predicting extubation failure after successful completion of a spontaneous breathing trial. Respir Care 2007;52:1710-7.

6. Schindler MB. Prediction of ventilation weaning outcome: Children are not little adults. Crit Care 2005;9:651-2.

7. Newth CJ, Venkataraman S, Willson DF, Meert KL, Harrison R, Dean JM, et al. Weaning and extubation readiness in pediatric patients. Pediatr Crit
Care Med 2009;10:1-11.

8. Park SH, Han SH, Do SH, Kim JW, Rhee KY, Kim JH, et al. Prophylactic dexamethasone decreases the incidence of sore throat and hoarseness after tracheal extubation with a double-lumen endobronchial tube. Anesth Analg 2008; $107: 1814-8$.

9. Karmarkar S, Varshney S. Tracheal extubation. Contin Educ Anaesth Crit Care Pain 2008;8:214-20.

10. Thiagarajan RR, Bratton SL, Martin LD, Brogan TV, Taylor D. Predictors of successful extubation in children. Am J Respir Crit Care Med 1999;160:1562-6.

11. Hubble CL, Gentile MA, Tripp DS, Criag DM, Meliones JN, Cheifetz IM. Deadspace to tidal volume ratio predicts successful extubation in infants and children. Crit Care Med 2002;28:2034-40.

12. Randolph AG, Wypij D, Venkataraman ST. Effect of mechanical ventilator weaning protocols on respiratory outcomes in infants and children: A randomized control trial. JAMA 2002;288:2561-8.

13. Sadowski R, Dechert RE, Bandy KP, Juno J, Bhatt-Mehta V, Custer JR, et al. Continuous quality improvement: Reducing unplanned extubations in a pediatric intensive care unit. Pediatrics 2004;114:628-32.

14. Oliveira RH, Filho AB. Incidence of acute lung injury and acute respiratory distress syndrome in the intensive care unit of a university hospital: A prospective study. J Bras Pneumol 2006;32:35-42.

15. Edmunds S, Weiss I, Harrison R. Extubation failure in a large pediatric ICU population. Chest 2001;119:897-900.

16. Manczur T, Greenough A, Pryor D, Rafferty GF. Weaning and extubation readiness in pediatric patients: Misperceptions about the impact of endotracheal tubes on weaning and spontaneous breathing trial. Crit Care Med 2000;28:2991-6.

17. Alvarado JG, Barragán LJ, Aguilera CM, Garza AA, Maltos VW. Incidence of failed extubations and risk factors associated in patients in the pediatric intensive care unit: Experience in a teaching hospital. Med Univ 2007;9:7-12.

18. Fontela PS, Piva JP, Garcia PC, Bered PL, Zilles K. Risk factors for extubation failure in mechanically ventilated pediatric patients. Pediatr Crit Care Med 2005;6:166-70.

19. Wratney AT, Benjamin DK Jr., Slonim AD, He J, Hamel DS, Cheifetz IM, et al. The endotracheal tube air leak test does not predict extubation outcome in critically ill pediatric patients. Pediatr Crit Care Med 2008;9:490-6.

20. de Souza Menezes F, Leite HP, Nogueira PC. Malnutrition as an independent predictor of clinical outcome in critically ill children. Nutrition 2012;28:267-70.

21. de Groot RI, Dekkers OM, Herold IH, de Jonge E, Arbous MS. Risk factors and outcomes after unplanned extubations on the ICU: A case-control study. Crit Care 2011;15:R19.

22. Vallverdú I, Calaf N, Subirana M, Net A, Benito S, Mancebo J, et al. Clinical characteristics, respiratory functional parameters, and outcome of a twohour T-piece trial in patients weaning from mechanical ventilation. Am J Respir Crit Care Med 1998;158:1855-62.

23. Engoren M, Buderer NF, Zacharias A, Habib RH. Variables predicting reintubation after cardiac surgical procedures. Ann Thorac Surg 1999;67:661-5.

Funding: None; Conflict of Interest: None Stated.

How to cite this article: Khurana S, Bhargava S, Pooni PA, Bhat D, Dhooria G, Goraya J, Arora K, Kakkar S. Risk factors for extubation failure in mechanically ventilated children in pediatric intensive care unit. Indian $\mathrm{J}$ Child Health. 2019; 6(7):379-382.

Doi: 10.32677/IJCH.2019.v06.i07.012 